\title{
Peertechz
}

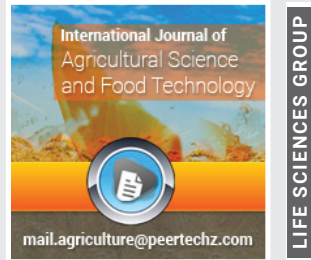

\section{Determination of the application} rate and Frequency of Nimbecidine for the effective management of pea aphid Acrythosiphon pisum (Homoptera: Aphididae) on field pea

\section{Dagne Kora* and Ermias Teshome}

Sinana Agricultural Research Center, P.O.Box-208, Bale-Robe, Ethiopia
Received: 02 December, 2021

Accepted: 30 December, 2021

Published: 31 December, 2021

*Corresponding author: Dagne Kora, Sinana Agricultural Research Center, P.O.Box-208, Bale-Robe, Ethiopia, Tel: +251912250880; E-mail: dagnekor@gmail.com

ORCID: https://orcid.org/0000-0001-9172-0502

Keywords: Pea aphid; Nimbecidine; Botanical; rate

Copyright License: ( 2021 Kora D, et al. This is an open-access article distributed under the terms of the Creative Commons Attribution License, which permits unrestricted use, distribution, and reproduction in any medium, provided the original author and source are credited.

https://www.peertechzpublications.com

Check for updates

\section{Abstract}

The development of botanical insecticides as a novel and safer alternative strategy, botanical insecticides which contain plant extracts as active components are safer as well as environmentally friendlier than synthetic insecticides. The field experiment was conducted at Ginir district with the objectives to evaluate the Nimbecidine insecticide against field pea aphid and to determine the application rate and frequencies for the effective management of field pea aphid. The experiment was laid out in RCBD design with three (3) replication. The treatments include five rate of nimbecidine $(3,3.5,4,4.5 \mathrm{~L} / \mathrm{ha})$ and three frequencies (0, 1,2 and 3$)$. Aphid population significantly affected by the rate and frequency of nimbecidine at the rate $4.5 \mathrm{lt} / \mathrm{ha}$ the mortality reached from 27.89 to $10.67 \%$ on two times sprayed plots. The highest yield advantage of $35.61 \%$ and $33.86 \%$ over the untreated control was obtained from the plots treated at the rate of 4.5 and $4 \mathrm{lt} / \mathrm{ha}$ when sprayed two times. Therefore, Their use in pea aphid IPM at the rate of $4.5 \mathrm{lt} / \mathrm{ha}$ at the frequency of two times application at flowering and pod setting stage provides good results.

\section{Introduction}

In the development and promotion of Integrated Pest Management (IPM), interest in using botanicals has gained attention in recent years. This is because of their benefit in reducing environmental pollution, minimum effect on nontarget organism and averting insecticide induced resistance among others [1]. Research on botanical control of insect pest in Ethiopia has so far concentrated on storage pest management [1]. Information on their potential against field pest is scanty. Development of bio control based IPM entails replacement of non-synthetic insecticides by selective and IPM compatible products. The misuse and excessive use of synthetic insecticide may cause some undesirable effects not only to the agricultural ecosystem but also to human health due to insecticide residue in food. Therefore, several efforts have been created to reduce the use of synthetic pesticides.

One of the efforts is the development of botanical insecticides as a novel and safer alternative strategy, botanical insecticides which contain plant extracts as active components are safer as well as environmentally friendlier than synthetic insecticides [2]. A number of insect pest species including pea aphid, Acrythosiphon pisum (Homoptera: Aphididae), Pod borer, Helcoverpa armigera (Lipdoptera: Noctuadae), Black bean aphid, Aphis fabae(Homoptera: Aphididae), Thrips, Taeniothrips nigricomis and leaf minor, Liriomyza brassicae inflicit damage on pulse crops in Ethiopia [3]. Of these, the pea aphid and pod borer are the most important in affecting the field pea production in Ethiopia.

Nimbecidine EC is a neem-oil-based botanical insecticide containing Azadirachtin and other limonoids including Meliantriol, Salanin, Nimbin and a host of other terpinoids in the ratio as it occurs naturally in Neem. Nimbecidine exhibits multiple modes of action. It acts as an: Antifeedant, Repellent, Ovi-position Deterrent, Antifeedant, Insect Growth Regulator, Sterilant.

\section{Features of Nimbecidine}

- Nimbecidine is a broad spectrum botanical insecticide. 
- Nimbecidine is a natural plant based botanical insecticide.

- Nimbecidine does not create resistance, resurgence or residue problems.

- Nimbecidine forms a good molecule for use in an IPM programme.

\section{Benefits of Nimbecidine}

- It effectively controls the economically important pests such as Whitefly, Aphids, Thrips, Mealy bugs, Caterpillars and Leafhoppers in a wide range of crops.

- Does not affect the natural enemies. Safe to use with beneficial parasites and predators and thus offers longlasting pest control.

- Helps to increase productivity by controlling the pests and improving crop health.

- It is eco-friendly and helps to maintain the Ecological Balance.

- Insects cannot develop resistance against Nimbecidine.

\section{- No residue.}

I evaluated Nimbecidine on field pea aphids with the compression of synthetic insecticide dimethoate at our experimental station and I observed that the efficacy of nimbecidine was less as compared to dimethoate. Hence, it may need the increment of the dosage and frequencies since the botanicals are degraded quickly. Therefore, I want to test its efficacy at different rates, the experiment was proposed with the following objective.

\section{Objective}

$>$ To determine the appropriate rate and frequencies for the effective management of pea aphid.

\section{Materials and methods}

\section{Treatments and experimental design}

The experiment was done at Agarfa research sub-site during 2017-2019 crop seasons. The experiment was laid out in RCBD design with three (3) replications. The treatments included five rate of nimbecidine $(3,3.5,4,4.5 \mathrm{~L} / \mathrm{ha})$ and three frequencies ( $0,1,2$ and 3). The plot was size of $4 \mathrm{~m} \mathrm{x} \mathrm{1.2m} \mathrm{with}$ 6 rows, $0.2 \mathrm{~m}$ apart. Recommended agronomic practices were followed for cultivation. Insecticides were sprayed during the crop growing season following the appearance of pea aphid and continued at 8 days intervals.

\section{Data to be collected}

Data on date of flowering, date of maturity, \%of infestation (No_ of aphid/plot), efficacy (No_ of aphid/plant) before and after spray, number of pods/plant, number of seed /pod, thousand seed weight and grain yield were collected.

\section{Data management and statistical analysis}

Both the field data (\%infestation, efficacy and agronomic data) and laboratory data (yield \&yield related data) were collected. Data were subjected to the analysis of variance using GLM Procedure SAS software (SAS 2002). The means were compared using Duncan's Multiple Range Test (DRMT) (Duncan, 1955) at 0.05 probability level.

\section{Result and discussion}

\section{Aphid population}

The activity of the Nimbicidine against pea aphid (Acrythosiphon pisum) at the four rates sprayed (3, 3.5, 4 and 4.5lt/ha). At $4.5 \mathrm{lt} /$ ha the mortality reached from 27.89 to $10.67 \%$ in the twice sprayed plots. The maximum percent of aphid infestation $(70.44 \%)$ after spray was recorded from untreated control and followed by Nimbicidine sprayed at the rate of 3 and $3.5 \mathrm{lt} / \mathrm{ha}(31.33 \%$ and $31.11 \%$, respectively while the lowest $(18.67 \%, 10.67 \%, 17.33)$ were recorded from Nimbicidine sprayed at the rate of $4.5 \mathrm{lt} / \mathrm{ha}$ on one, two and three times treated plots, respectively. The observed lower number of pea aphids in the high rate of application than the low rate agrees with reports of Swaminathan, et al. [4]. They reported a higher percentage (73.3\%) of Adonia variegata (Goeze) mortality from a $10 \%$ neem seed kernel extract than a $5 \%$ neem seed oil which caused $65 \%$ mortality.

\section{Yield and yield components}

Analysis of variance for grain yield depicted that there was a significant difference $(\mathrm{P}<0.05)$ between treatments (Table 1). Yields in kg/ hectare ranged between 3385 and 5257.08 among treatments. The highest grain yield of $5257.08 \mathrm{~kg} / \mathrm{ha}$, $5118.02 \mathrm{~kg} / \mathrm{ha}$ were harvested from Nimbicidine sprayed at the rate of 4.5lt/ha and 41/ha on th e plot sprayed twice, respectively. Whereas, the lowest grain yield of $3385 \mathrm{~kg} / \mathrm{ha}$ was harvested from untreated plots followed by the plot sprayed at the rate of $3 \mathrm{lt} / \mathrm{ha}(3487.71 \mathrm{~kg} / \mathrm{ha})$ and $3.5 \mathrm{l} / \mathrm{ha}(3439.90 \mathrm{~kg} / \mathrm{ha})$ (Table 1).

Pods per plant, seeds per pod and thousand seed weight ranged between $8.1-11,4.3-4.87$ and 170.60 and $182.53 \mathrm{gm}$, respectively (Table 1 ). The differences between the rates were not significant for pods per plant, seeds per pod and thousand seed weight. Differences between different rates of Nimbicidine for yield was significant. The lowest values for all yield and yield component variables were obtained from the untreated plots and from the lowest rates of Nimbicide( at the rate of 3 and $3.5 \mathrm{lt} / \mathrm{ha}$ ) and the highest were obtained from higher rates ( 4 and $4.5 \mathrm{lt} / \mathrm{ha}$ ) treatment. The yield advantage of $35.61 \%$ and $33.86 \%$ over the untreated control was obtained from the plots treated at the rate of 4.5 and $4 \mathrm{lt} / \mathrm{ha}$ when sprayed twice.

\section{Simple regression analysis between aphid infestation \% age and yield}

The estimated slope of the regression line obtained for the field pea yield was -10.37 . The estimate showed that for each unit increase in percent infestation of aphid, there was a grain 
yield loss of $10.37 \mathrm{~kg} /$ ha (Figure 1) Based on the coefficient of determination $\left(\mathrm{R}^{2}\right)$ value, the equations explained about $12 \%$ of variation in yield due to aphid infestation.

\section{Cost/benefit analysis}

The result showed that Nimbicidine twice sprayed plots at the rate of $4.5 \mathrm{l} /$ ha provided the highest gross returns (ETB $165,585 / \mathrm{ha}$ ) and the lowest gross return ETB 106,610.00/ ha was obtained from the untreated check. The plot sprayed with Nimbicidine sprayed plots at the rate of $4.5 \mathrm{l} /$ ha gave the maximum net return ETB 150, 238.80 /ha and also gave the highest benefit cost ratio (9.79). Nimbicidine once sprayed plots at the rate of $4.5 \mathrm{l}$ /ha plots also provided the higher gross returns (ETB 155,750/ha) and gave the higher net return ETB 142,235 / ha and also gave the higher benefit cost ratio (10.52).
The highest (ETB 358.96) marginal rate of return was obtained from Nimbicidine twice sprayed plots at the rate of $4.5 \mathrm{l} / \mathrm{ha}$. In other words, for every ETB 1.00 investment in Nimbicidine at the rate of $4.51 /$ ha cost and spraying, there was a gain of ETB 3.59. Therefore the most economic benefit for pea aphid management was obtained from Nimbicidine twice sprayed plots at the rate of $4.51 /$ ha Table 2 .

\section{Conclusions and recommendations}

Results of the study showed that Nimbicidine insecticide at 4lt/ha and $4.5 \mathrm{lt} / \mathrm{ha}$ application rate can reduce pea aphid population and their damage on field pea. The pesticidal characterstics of extracts from different parts of the neem tree, Azadirachta indica against several pests of crops are well documented [5,6]. The observed lower number of pea aphids in

Table 1: Effect of rate and frequencies of Nimbicidine insecticide on aphid infestation, yield and yield components at Agarfa in 2017-2019 GC cropping season.

\begin{tabular}{|c|c|c|c|c|c|c|c|c|c|}
\hline No. & Rate & Frequency & $\begin{array}{c}\% \text { age infestation before } \\
\text { spray }\end{array}$ & $\begin{array}{l}\% \text { age infestation After } \\
\text { spray }\end{array}$ & $\begin{array}{l}\text { Pod per } \\
\text { plant }\end{array}$ & $\begin{array}{l}\text { Seed per } \\
\text { pod }\end{array}$ & HSW & Yield (kg/ha) & Yield advantage Over control \\
\hline 1 & $\mathrm{R} 1$ & F1 & 30.34 & 29.89 & 8.87 & 4.77 & 180.07 & 3941.35 & 14.12 \\
\hline 2 & R1 & $\mathrm{F} 2$ & 38.22 & 28.78 & 9.67 & 4.6 & 182.53 & 4551.98 & 25.64 \\
\hline 3 & R1 & F3 & 53 & 31.11 & 9.13 & 4.37 & 168.93 & 3487.71 & 2.9 \\
\hline 4 & R2 & F1 & 26.22 & 31.33 & 8.1 & 4.58 & 177.33 & 4001.77 & 15.41 \\
\hline 5 & R2 & $\mathrm{F} 2$ & 29.33 & 24.32 & 11 & 4.73 & 176.6 & 3439.90 & 1.6 \\
\hline 6 & R2 & F3 & 45.22 & 17.89 & 10.67 & 4.37 & 174.47 & 4620.83 & 26.74 \\
\hline 7 & R3 & F1 & 66.22 & 22.56 & 11 & 4.67 & 168.8 & 4513.44 & 25.00 \\
\hline 8 & R3 & $\mathrm{F} 2$ & 86.11 & 30.22 & 9 & 4.47 & 173.07 & 5118.02 & 33.86 \\
\hline 9 & R3 & F3 & 52.78 & 21.33 & 10.53 & 4.73 & 172.8 & 3786.35 & 10.60 \\
\hline 10 & $\mathrm{R} 4$ & $\mathrm{~F} 1$ & 39.11 & 18.67 & 9 & 4.87 & 172.33 & 4945 & 31.55 \\
\hline 11 & R4 & $\mathrm{F} 2$ & 27.89 & 10.67 & 10.57 & 4.73 & 178.13 & 5257.08 & 35.61 \\
\hline 12 & R4 & F3 & 24 & 17.33 & 9.53 & 4.53 & 174.2 & 4860.63 & 30.36 \\
\hline & \multicolumn{2}{|c|}{ Control } & 35.33 & 70.44 & 9.77 & 4.57 & 170.6 & 3385 & \\
\hline \multicolumn{3}{|c|}{ CV (\%) } & & 32.60 & 26.58 & 7.05 & 5.13 & 18.49 & \\
\hline \multicolumn{3}{|c|}{ LSD (0.05) } & 35.97 & 10.34 & 3.47 & 0.43 & 12.04 & 1084.6 & \\
\hline
\end{tabular}

Note: R1: Rate1; R2: Rate2; R3: Rate3 and R4: Rate4; F1: Frequency 1 times; F2: Frequency 2 times and F3: Frequency 3 times

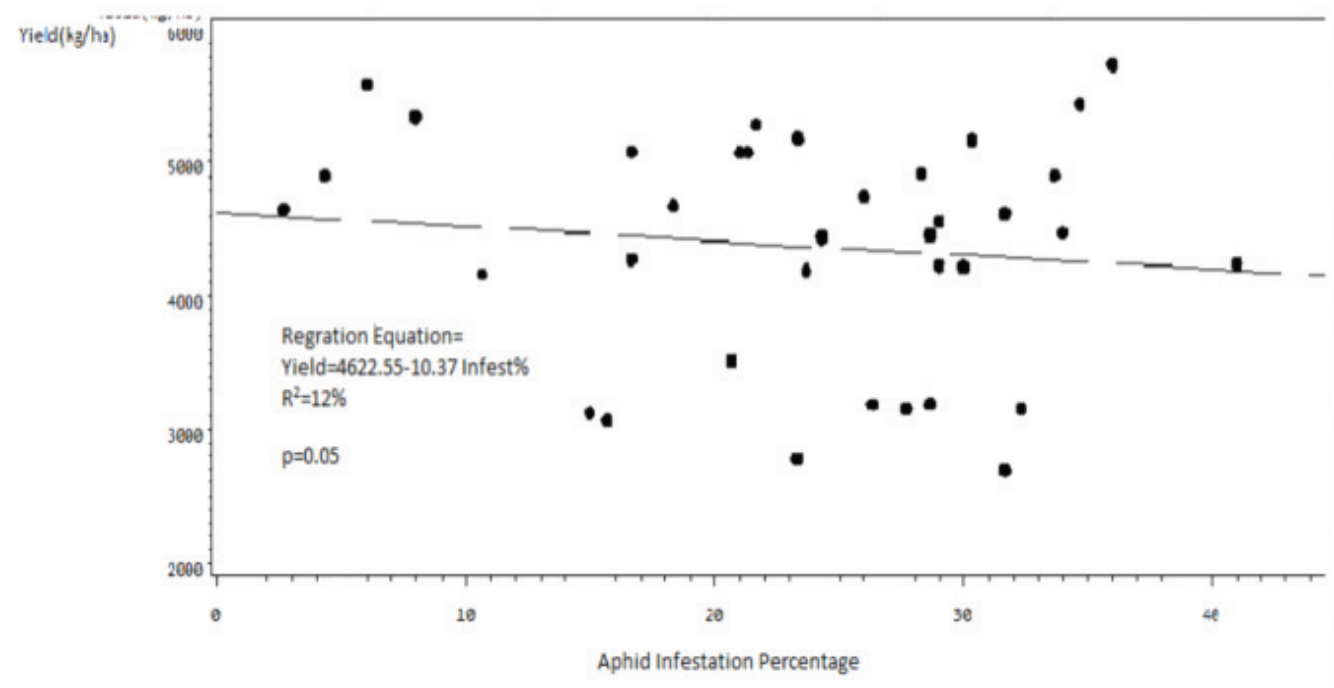


Table 2: Cost-benefit analysis of Nimbicidine application rate and frequencies against pea aphid on field pea during 2017/19 GC Season at Agarfa.

\begin{tabular}{|c|c|c|c|c|c|c|c|c|c|c|}
\hline Rate & Frequency & $\begin{array}{l}\text { Yield obtained } \\
\text { (qt/ha) }\end{array}$ & Adjusted & $\begin{array}{c}\text { Sale price } \\
\text { (ETB/qt) }\end{array}$ & $\begin{array}{l}\text { Total Variable } \\
\text { Cost (ETB/ha) }\end{array}$ & $\begin{array}{c}\text { Gross Return } \\
\text { (Price x Qt) }\end{array}$ & $\begin{array}{l}\text { Net Return } \\
\text { (GR-TVC) }\end{array}$ & $\begin{array}{l}\text { Benefit cost ratio } \\
\text { (GMP/TVC) }\end{array}$ & $\begin{array}{c}\text { MRR } \\
\text { (NR-NR of } \\
\text { Control /TVC) }\end{array}$ & MRR \% \\
\hline R1 & F1 & 39.41 & 35.5 & 3500 & 12810 & $124,250.00$ & $111,440.00$ & 8.70 & 1.27 & 127.16 \\
\hline R1 & F2 & 45.6 & 41.04 & 3500 & 14170.8 & $143,640.00$ & $129,469.20$ & 9.14 & 2.42 & 242.1769 \\
\hline R1 & F3 & 34.88 & 31.4 & 3500 & 15228 & $109,900.00$ & $94,672.00$ & 6.22 & -0.03 & -3.14421 \\
\hline R2 & F1 & 40.1 & 36.09 & 3500 & 12996.8 & $126,315.00$ & $113,318.20$ & 8.72 & 1.40 & 139.7836 \\
\hline R2 & F2 & 34.4 & 30.96 & 3500 & 14319.2 & $108,360.00$ & $94,040.80$ & 6.57 & -0.08 & -7.75183 \\
\hline R2 & F3 & 46.21 & 41.59 & 3500 & 15956.8 & $145,565.00$ & $129,608.20$ & 8.12 & 2.16 & 215.9418 \\
\hline R3 & F1 & 45.13 & 40.62 & 3500 & 13262.4 & $142,170.00$ & $128,907.60$ & 9.72 & 2.55 & 254.5301 \\
\hline R3 & F2 & 51.18 & 46.06 & 3500 & 14971.4 & $161,210.00$ & $146,238.60$ & 9.77 & 3.41 & 341.236 \\
\hline R3 & F3 & 37.86 & 34.07 & 3500 & 16331.4 & $119,245.00$ & $102,913.60$ & 6.30 & 0.48 & 47.53297 \\
\hline R4 & F1 & 49.45 & 44.5 & 3500 & 13515 & $155,750.00$ & $142,235.00$ & 10.52 & 3.48 & 348.3848 \\
\hline R4 & F2 & 52.57 & 47.31 & 3500 & 15346.2 & $165,585.00$ & $150,238.80$ & 9.79 & 3.59 & 358.9683 \\
\hline R4 & F3 & 48.61 & 43.75 & 3500 & 17050 & $153,125.00$ & $136,075.00$ & 7.98 & 2.40 & 240.0246 \\
\hline \multicolumn{2}{|c|}{ Control } & 33.85 & 30.46 & 3500 & 11459.2 & $106,610.00$ & $95,150.80$ & 8.30 & 0.00 & \\
\hline
\end{tabular}

the high rate of application than the low rate agrees with reports of Swaminathan, et al. [4]. They reported a higher percentage $(73.3 \%)$ of Adonia variegata (Goeze) mortality from a $10 \%$ neem seed kernel extract than a $5 \%$ neem seed oil which caused $65 \%$ mortality. The plot sprayed with Nimbicidine sprayed plots at the rate of 4.5 l/ha gave the maximum net return ETB 150, 238.80 /ha. The highest (ETB 358.96) marginal rate of return was obtained from Nimbicidine twice sprayed plots at the rate of $4.5 \mathrm{l} / \mathrm{ha}$. Synthesized Nimbicidine was able to provide varying degree of protection on pea from pea aphid attack and safer to pea aphid natural enemies than the synthetic insecticide suggesting their potential in the Integrated Management of the Pest (IPM). Therefore, Nimbicidine twice sprayed plots at the rate of $4.5 \mathrm{l} / \mathrm{ha}$ application was recommended for the management of field pea aphid.

\section{References}

1. Sitotaw L, Ayalew G, Tefera T (2008) Effect of neem based insecticide on cabbage aphid (Brevicoryne brassicae) and its predator in the central Rift valley of Ethiopia. Pest management journal of Ethiopia 12: 59-66.

2. Dadang D, Fitriasari ED, Prijono D (2009) Effectiviness of two Botanical insecticide formulations to two major cabbage insect pest on field application. J. ISSAAS 15: 42-51. Link: https://bit.ly/3sLhpS6

3. Ali K, Habtewold T (1994) Research on insect pests of cool-season food legumes. 367-396. In: A. Telaye, Geletu Bejiga, M.C. Saxena and M.B.Solh (eds.). Cool Season Food Legumes of Ethiopia Proceedings of 1st National Cool Season Food Legumes Review Conference. Addis Ababa, Ethiopia. Link: https://bit.ly/3pDguB4

4. Swaminathan $R$, Jat $H$, Hussain $T$ (2010) Side effects of a few botanicals on the aphidophagous coccinellids. J Biopestic 3: 081-084. Link: https://bit.ly/3Hm5Qop

5. Schmutterer H (1990) Properties and potential of natural pesticides from the neem tree, Azadirachta indica. Annu Rev Entomol 35: 271-297. Link: https://bit.ly/32NdXv7

6. Ali K (1991) Yield loss assessment for pea aphid. (A.pisum). 372-373. Results of research on cool season Food Legumes in Ethiopia under IAR/ICARDA/ SAREC during 1987 Crop season. IAR, Addis Ababa.

\footnotetext{
Discover a bigger Impact and Visibility of your article publication with Peertechz Publications

Highlights

* Signatory publisher of ORCID

* Signatory Publisher of DORA (San Francisco Declaration on Research Assessment)

* Articles archived in worlds' renowned service providers such as Portico, CNKI, AGRIS, TDNet, Base (Bielefeld University Library), CrossRef, Scilit, J-Gate etc.

* Journals indexed in ICMJE, SHERPA/ROMEO, Google Scholar etc.

* OAl-PMH (Open Archives Initiative Protocol for Metadata Harvesting)

* Dedicated Editorial Board for every journal

* Accurate and rapid peer-review process

* Increased citations of published articles through promotions

* Reduced timeline for article publication

Submit your articles and experience a new surge in publication services (https://www.peertechz.com/submission).
}

Peertechz journals wishes everlasting success in your every endeavours. 